\title{
The Impact of Wind Power Development on Haze in Beijing-Tianjin-Hebei region of China
}

\author{
Liming Liu \& Liye Xie \\ Department of North China Electric Power University
}

Keywords: Beijing-Tianjin-Hebei region, haze, wind power farm, atmospheric circulation, offshore wind power.

\begin{abstract}
In this paper, we research on the haze development in Beijing-Tianjin-Hebei region. Considering the wind power development is synchronous with haze development in the upstream of the region, we infer that the wind power farm have a significant effect on atmosphere of the lower drift region. First, we discuss the impact of wind power farm on the wind speed of this region. Then, we analyze the impact of wind power on the atmospheric circulation of this region combined with Butterfly Effect innovatively. Finally, we put forward reasonable suggestions of slowing down the wind power development in onshore areas and strengthening the construction of offshore wind power.
\end{abstract}

\section{Current wind power distribution in china}

According to Chinese Academy of Meteorological Sciences, the total reserves of wind energy in the ten meters height levels is 3.226 billion kw in China onshore, which ranks first in the world. The actual onshore reserves of wind energy which can be developed is 253 million $\mathrm{kW}$, and the actual offshore reserves of wind energy is three times than that it. So, the total reserves of wind energy which can be developed is about 10 billion $\mathrm{kW}$. In other words, if the wind resource development reaches to $60 \%$, only the wind power can support all the China's current annual electricity needs.

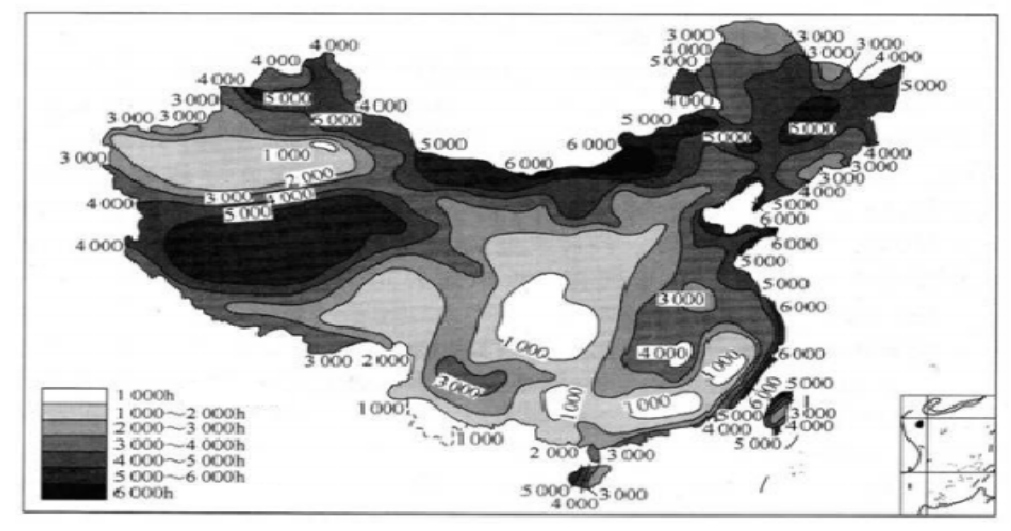

Figure1 the generating capacity of national wind power plants

Seen from Figure 1, the wind power is concentrated among the northwest region, the northeast region, the upper drift of Beijing-Tianjin-Hebei region and the Inner Mongolia region. Their annual generation duration are more than 6000 hours.

\section{The impact of wind power on the atmosphere}

\subsection{The reducing impact of wind power farm on the wind speed of local area}

Zongci Zhao, the professor in the center for Earth System Science, Tsinghua University, said that, "It has drawn a unanimous conclusion at home and abroad that wind power filed has a significant effect on wind speed of local area, causing the reduction of wind speed in the lower drift region.” 
A great many of observation data indicate what professor Zhao says. At the same time, the downstream temperature will vary up and down apparently due to the stability difference of surface layer in the local area. According to the observation data of a wind filed in Denmark, we can know something after calculation. If the wind speed coming into the wind farm is $8 \sim 9 \mathrm{~m} / \mathrm{s}(\mathrm{e} . \mathrm{g} .8 .6 \mathrm{~m} / \mathrm{s})$, the wind speed will reduce apparently observed in the lower drift region after the operating absorption of wind power filed to momentum, the frictional effect of $70 \mathrm{~m}$ height wind turbine and the wind speed in the $6 \mathrm{~km}$ of lower drift and the original wind speed ratio is 0.86 and in $8 \mathrm{~km}$, the ratio is 0.88 . It will rise to 0.9 in $11 \mathrm{~km}$ slowly afterwards and has not been restored to the original level (Figure 2).

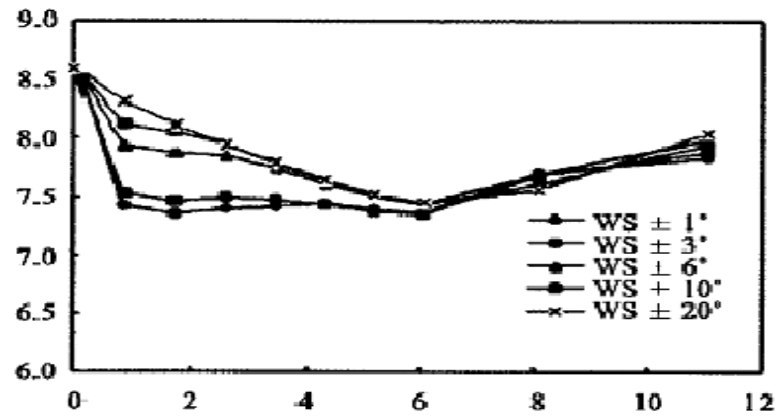

Fig. 2 Wind speed damping (unit: $\mathrm{m} / \mathrm{s}$ ) with downwind distances (unit: $\mathrm{km}$ ) at a wind farm of Denmark (different curves correspond to widths of wind direction azimuth, the azimuth of wind direction WS from \pm 1 "to \pm 20 ”

Integrating all the above information, we know that the wind power bases in the Beijing-Tianjin-Hebei region are like a natural barrier. They reduce the intensity of the monsoon from Mongolia - Siberia and cause that the pollution is hard to spread. Thus, haze aggravated.

\subsection{The impact of wind power on the atmospheric circulation in the Beijing-Tianjin-Hebei region}

Beijing-Tianjin-Hebei region nears the Yanshan Mountains in the north, the Taihang mountains in the west, and the Bohai Sea in the east. The region has cities such as Beijing, Tianjin, Shijiazhuang, and Tangshan and so on. The south and the southeast of Beijing is flat. Beijing is located in the Taihang Mountains and Yanshan Mountain at the junction of the plains. Under this condition, the valley wind and city heat island circulation often influence each other. Thus the atmospheric circulation in Beijing area of low layer has some particularity. Also, it will make the transport of pollutants become more complex.

In the process of absorption of wind power generation, the wind turbine will not only cause the decrease of horizontal direction, but also make the air change in the vertical direction, influencing special atmospheric circulation in the Beijing-Tianjin-Hebei region like a "low wall" when many wind turbines are heavily concentrated in one region. The wind power bases in north and northwest of this region play the role of wind wall.

We use the "Butterfly Effect" theory boldly. After gradual accumulation, tiny impact will be amplified and become a great impact. We can infer that the tiny impact of wind power farm will become an impact of wind power that cannot be ignored on the atmospheric circulation in the Beijing-Tianjin-Hebei region.

\section{Proposals for future development of wind power}

We suggest that mitigating appropriately the construction speed of the wind farm which lay in the wind upstream of Beijing-Tianjin-Hebei region and putting greater effort to develop offshore wind power.

Offshore wind has many advantages compared with its onshore counterpart: when wind flow over the rough surface of ground or obstacle, both the speed and direction of wind will change; while the sea surface is much smoother, the speed of offshore wind can usually be about $25 \%$ higher than that 
of coastal land. What is more, the intensity of offshore wind is smaller, with a stable dominant wind direction, which makes the turbines live a longer life. The development of offshore wind energy is less limited by noise, landscape, birds, electromagnetic interference and other issues; offshore wind farms do not involve land acquisition and other issues, for more concentrated population and endangered marine countries or regions, it is more suitable to develop offshore wind power. The development of offshore wind energy utilization will not cause air pollution and produce any harmful substances, it can also eliminates the influence of the inland city weather and reduce greenhouse gas emissions, so is of high environmental value.

\section{Conclusion}

Whether it is from the theory analysis and combined with the actual situation of Beijing- TianjinHebei region, the distribution of wind power plants have a certain effect on the formation of haze in its lower region. It is because the large scale distribution of wind power plants absorb the monsoon from the Inner Mongolia region. Thus, the wind speed decreases obviously. In the vertical direction, wind power farm also has some influence on local atmospheric circulation in the whole region. It makes the original atmospheric circulation has certain change. Ultimately, haze is more and more serious, and the environment is getting worse and worse.

With the exposure of the disadvantages in onshore wind farm, we put forward a method to develop offshore wind power. Offshore wind power has so many advantages such as the great dominant wind direction stability, small wind turbulence intensity at sea, less impact on the environment and so on. We believe that it will have good growth prospects.

\section{References}

[1] Frandsen S T, 2009. The making of a second generation wind farm efficiency model complex. Wind Energy, 12:445-458.

[2] Mikel de Prada Gil, 2014. Technical and economic assessment of offshore wind power plants based on variable frequency operation of clusters with a single power converter. Applied Energy.125:218-229.

[3] Shuhua Liu, 2008. Strategic Thinking of Sustainability for the Coupling Effect of Local Atmospheric Circulations over the Area of Beijing, Tianjin and Hebei province. Frontier Science. 2(8):61-74.

[4] Zongci Zhao, 2011. Advances in Assessment on Impacts of Wind Farms upon Climate Change. Advances in Climate Change Research, 7(6):400-406. 